\title{
Repeated reuse of deoxyribozyme-based logic gates
}

\author{
Bradley I Harding, ${ }^{\dagger}$ Nina M Pollak, ${ }^{\dagger, t}$ Darko Stefanovic, ${ }^{\S, \perp}$ Joanne Macdonald ${ }^{\dagger}, \|^{*}$
}

${ }^{\dagger}$ Genecology Research Centre, School of Science and Engineering, University of the Sunshine Coast, Sippy Downs, QLD, Australia

CSIRO Synthetic Biology Future Science Platform

${ }^{\S}$ Department of Computer Science, University of New Mexico, Albuquerque, New Mexico, USA

${ }^{\perp}$ Center for Biomedical Engineering, University of New Mexico, Albuquerque, New Mexico, USA

$\|_{\text {Division of Experimental Therapeutics, Department of Medicine, Columbia University, New }}$ York, NY, USA

*Email: jmacdon1@usc.edu.au; Phone:+617 54565944 
Table of contents

1. Materials and Methods

$\begin{array}{ll}\text { 1.1 Oligonucleotides } & \text { S3 }\end{array}$

1.2 Functional Testing S3

2. Supporting Figures and Tables

Figure $S 1 \quad$ S6

$\begin{array}{ll}\text { Figure S2 } & \text { S7 }\end{array}$

$\begin{array}{lr}\text { Figure S3 } & \text { S8 }\end{array}$

$\begin{array}{ll}\text { Figure S4 } & \text { S9 }\end{array}$

$\begin{array}{lr}\text { Figure S5 } & \text { S10 }\end{array}$

$\begin{array}{lr}\text { Figure S6 } & \text { S11 }\end{array}$

$\begin{array}{lr}\text { Table S1 } & \text { S12 }\end{array}$

$\begin{array}{lr}\text { Table S2 } & \text { S14 }\end{array}$

$\begin{array}{lr}\text { Table S3 } & \text { S15 }\end{array}$ 


\section{Materials and Methods}

\subsection{Oligonucleotides}

All dual-labelled DNA-RNA chimeric oligonucleotides marked as substrates were procured through TriLink Biotechnologies (California, USA), and all other oligonucleotides (marked as deoxyribozymes (DNAzymes), inputs, ANTI-inputs, and secondary quenchers) were procured through Integrated DNA Technologies (Iowa, USA). All oligonucleotides were resuspended in ultra-pure nuclease-free water (Astral Scientific, NSW, Australia).

The sequences for YES $\mathrm{SREEN}_{\text {, }} \mathrm{i}_{\mathrm{GREEN} 5}, \mathrm{i}_{\mathrm{RED} 5}$, and ANTI-S $\mathrm{GREEN}_{\mathrm{GR}}$ have been previously published by Poje et al. ${ }^{22}$ The catalytic core of $\mathrm{YES}_{\mathrm{RED}}{ }^{22}$ has been exchanged to result in an 8-17 DNAzymebased logic gate. YES $\mathrm{BLUE}_{\mathrm{B}}$ and its input $\mathrm{i}_{\mathrm{BLUE5}}$ were designed based on the 8-17 catalytic core and regions conserved between GREEN and RED oligonucleotides, with the substrate, its respective domain, and all other sections of the YES random sequence generator. To design 3 ' toeholds for the inputs, we shifted the 5 ' toeholds without any sequence alterations. All ANTI-inputs were made to be complementary to the toeholds of the inputs, extending eight nucleotides into the input sequence. The sequences for ANTI-S $\mathrm{RED}_{\mathrm{R}}$ and ANTI-S $\mathrm{BLUE}$ were made to complementary to the fluorophore-bound half of $\mathrm{S}_{\mathrm{RED}}$ and $\mathrm{S}_{\mathrm{BLUE}}$ respectively. Sequences are listed in Table S1.

Folded structures and free energy values of all oligonucleotide sequences were analysed by mfold, ${ }^{23}$ a freely available nucleic acid folding and hybridization predicting webtool. We note parameters for the folding temperature and magnesium concentration were changed to $25^{\circ} \mathrm{C}$ and $1.0 \mathrm{mM}$ respectively, and all other parameters were set as default.

\subsection{Functional testing}

Basic computing reactions contained 50nM DNAzyme, 100nM input single-stranded DNA (ssDNA), and 250nM substrate in tic-tac-toe buffer (40mM HEPES, 800mM NaCl, $800 \mu \mathrm{M} \mathrm{ZnCl}_{2}$, 
$\mathrm{pH} 7.0$ ), totaling $50 \mu \mathrm{L}$. For testing the deactivation of DNAzymes via the addition of inputcomplement ssDNA (ANTI-input), ANTI-input was added after 15 minutes of monitored activity at a concentration of $10 \mu \mathrm{M}$ in $1 \mu \mathrm{L}$, with testing of DNAzyme reactivation adding an additional $20 \mu \mathrm{M}$ of input ssDNA in $1 \mu \mathrm{L}$ after a further 15 minutes of monitoring. When testing the cyclability of ON and OFF states for the DNAzymes, all additions of input and ANTI-input were at $10 \mu \mathrm{M}$ in $1 \mu \mathrm{L}$, alternating at 15 minute intervals. For testing the effectiveness of the secondary quenchers for suppressing the fluorescence of their respective substrates, secondary quenchers were added at concentrations between $12.5 \mu \mathrm{M}$ and $6.875 \mu \mathrm{M}$ in $1 \mu \mathrm{L}(100 \%-55 \%$ concentration relative to substrate) to a basic computing reaction that had been left in the dark at room temperature overnight (16 hours) to reach maximum possible fluorescence. When testing the iteration of the designed system, OFF additions were $10 \mu \mathrm{M}$ ANTI-input and $12.5 \mu \mathrm{M}$ secondary quencher in $1 \mu \mathrm{L}$, and $\mathrm{ON}$ additions were $10 \mu \mathrm{M}$ input ssDNA and $12.5 \mu \mathrm{M}$ substrate in $1 \mu \mathrm{L}$, with alternating additions to the reaction being made every 15 minutes.

All reactions were prepared in 384-well plates (non-binding, black clear-bottom wells; Corning, New York, USA), with fluorescence being monitored by an EnSpire Multimode Plate Reader (PerkinElmer, Massachusetts, USA), reading fluorescence every minute. Excitation and emission wavelengths for each substrate were: $558 \mathrm{~nm}$ and $585 \mathrm{~nm}$ for SRED (TAMRA - BHQ2); 496nm and $520 \mathrm{~nm}$ for $\mathrm{S}_{\text {GREEN }}$ (fluorescein - BHQ1), and; 404nm and 458nm for $\mathrm{S}_{\mathrm{BLUE}}$ (pacific blue - dabcyl). For all reactions, background fluorescence of the substrates was measured as tic-tac-toe buffer containing only the substrate, and fluorescence values for a basic computing reaction were used as a baseline for normalisation. For data reflecting rate-of-activity for DNAzymes, the Microsoft Excel built-in line-of-best-fit by least-squares function was used per computing reaction, after all 
data points had been normalised. All reactions were run as duplicates per trial, and each trial was repeated at least twice, with mean and standard deviation been calculated across all same reactions.

\section{References}

(22) Poje, J. E.; Kastratovic, T.; Macdonald, A. R.; Guillermo, A. C.; Troetti, S. E.; Jabado, O. J.; Fanning, M. L.; Stefanovic, D.; Macdonald, J. Visual Displays that Directly Interface and Provide Read-Outs of Molecular States via Molecular Graphics Processing Units. Angew Chem Int Ed 2014, 53, 9222-5.

(23) Zuker, M. Mfold web server for nucleic acid folding and hybridization prediction. Nucleic Acids Res 2003, 31, 3406-15. 


\section{Supporting Figures and Tables}

a)

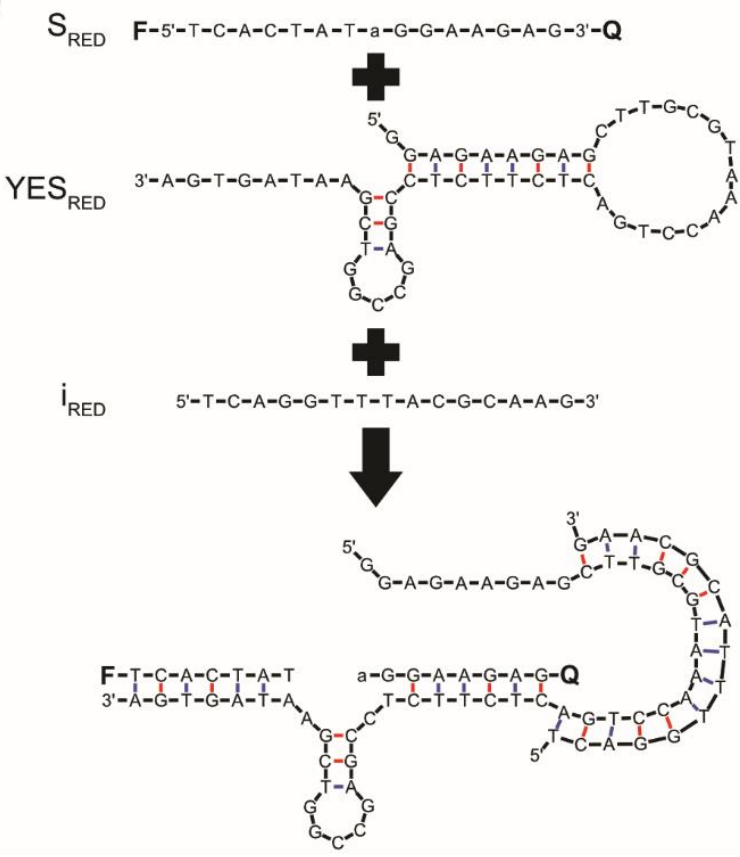

b)

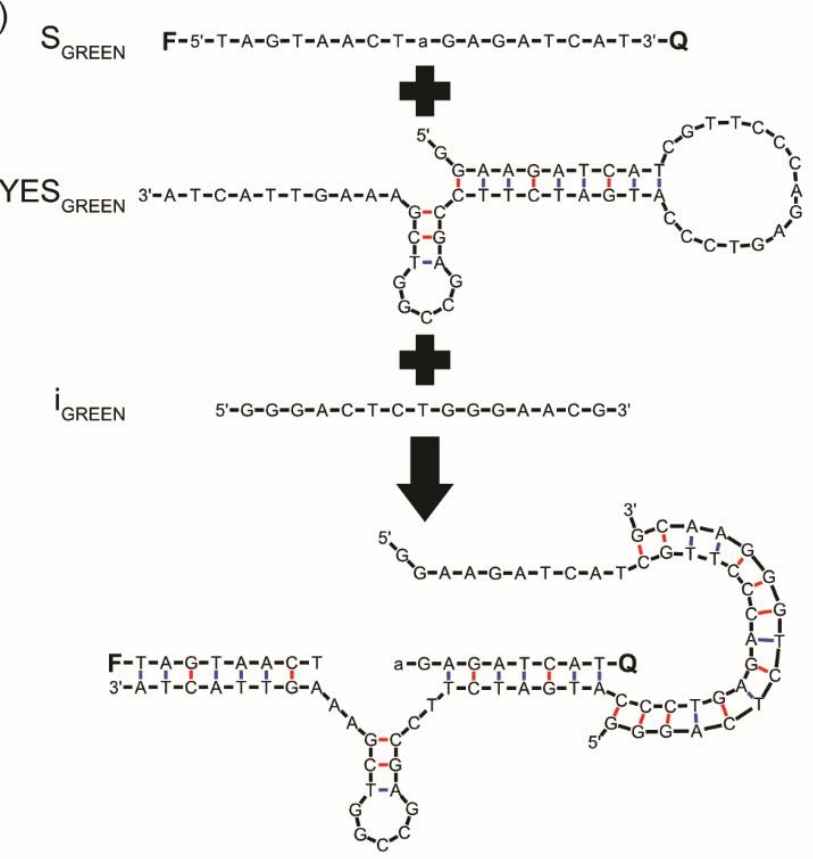

Figure S1. a) Interaction between the substrate $S_{\text {RED }}$, the DNAzyme $Y_{E S} S_{R E D}$, and its input $i_{\text {RED }}$, resulting in the enzymatic cleavage of the substrate. b) Interaction between the substrate $\mathrm{S}_{\text {GREEN, }}$ the DNAzyme YES ${ }_{\text {GREEN }}$, and its input $i_{\text {GREEN }}$, resulting in the enzymatic cleavage of the substrate. 
a)
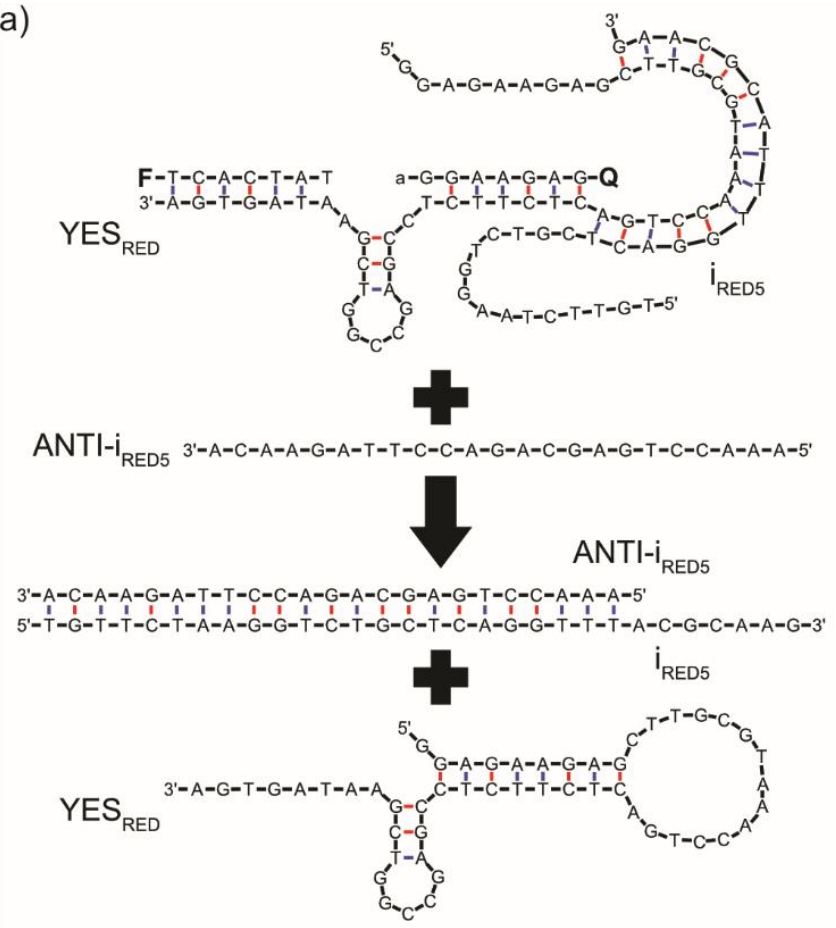

b)

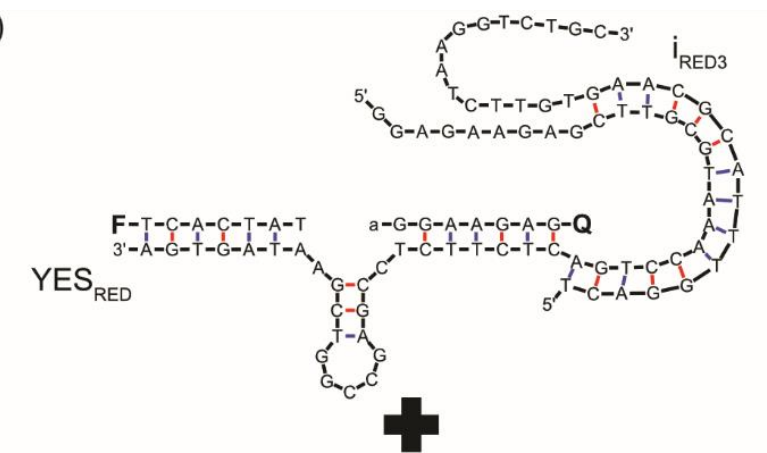

ANTI-I $_{\text {RED3 }}$ 3'-A-T-G-C-G-T-T-C-A-C-A-A-G-A-T-T-C-C-A-G-A-C-G-5'

ANTI-i RED3

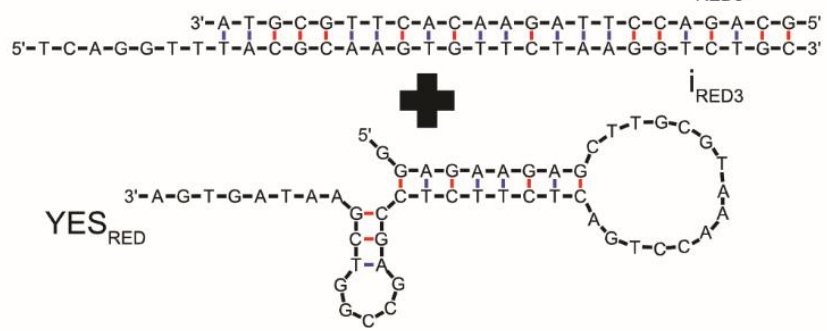

c)
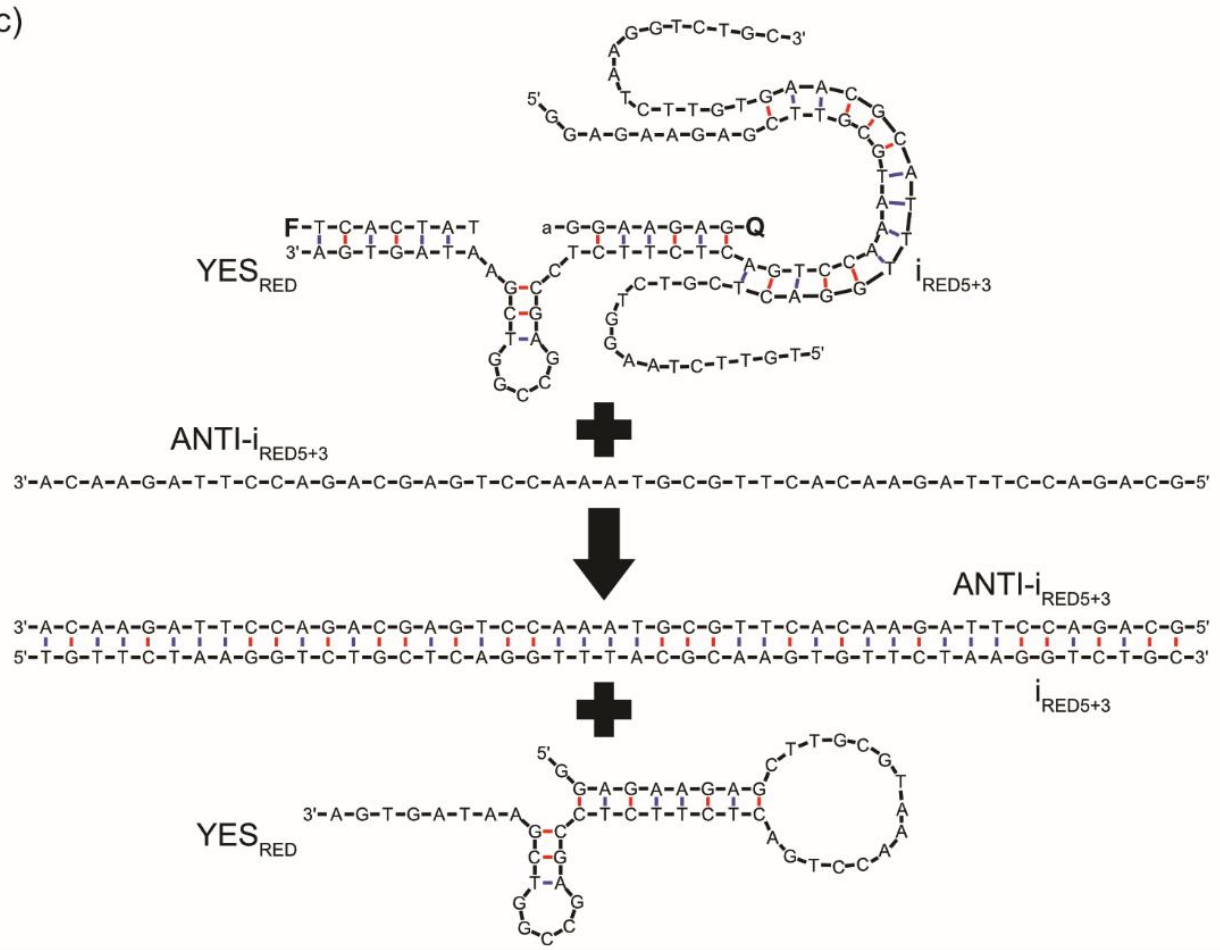

$\mathrm{i}_{\text {RED } 5+3}$

Figure S2. Interactions between the DNAzyme, YESRED, activated with one of its three input variants with an extended toehold region, and the inputs' respective ANTI-input, resulting in the formation of an input/ANTI-input complex and the deactivation of the DNAzyme. a) Interactions

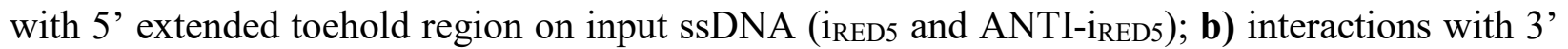

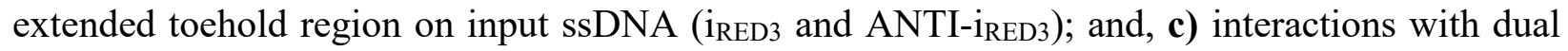
extended toehold regions on input ssDNA (iRED5+3 and ANTI-i RED5 +3$)$. 
a)
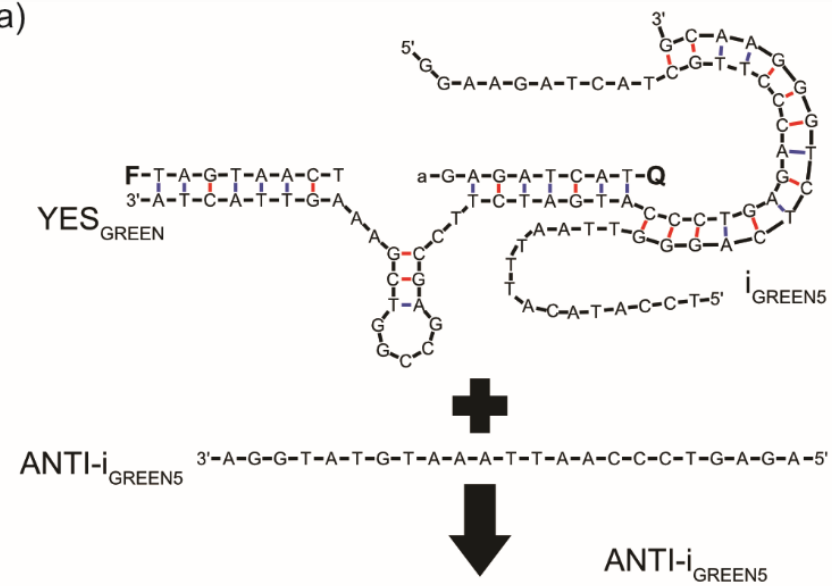

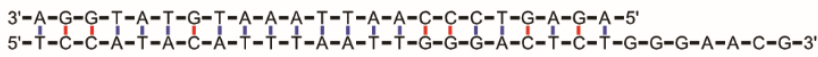

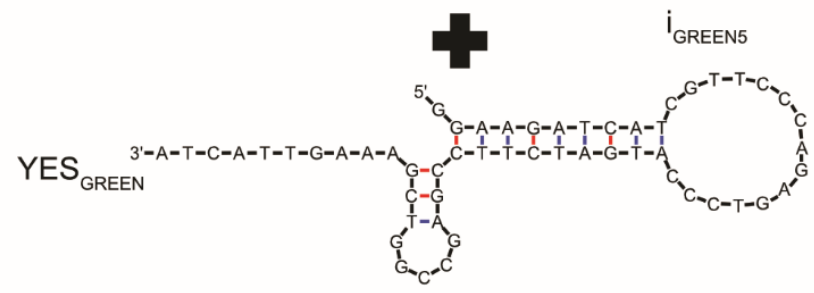

c)

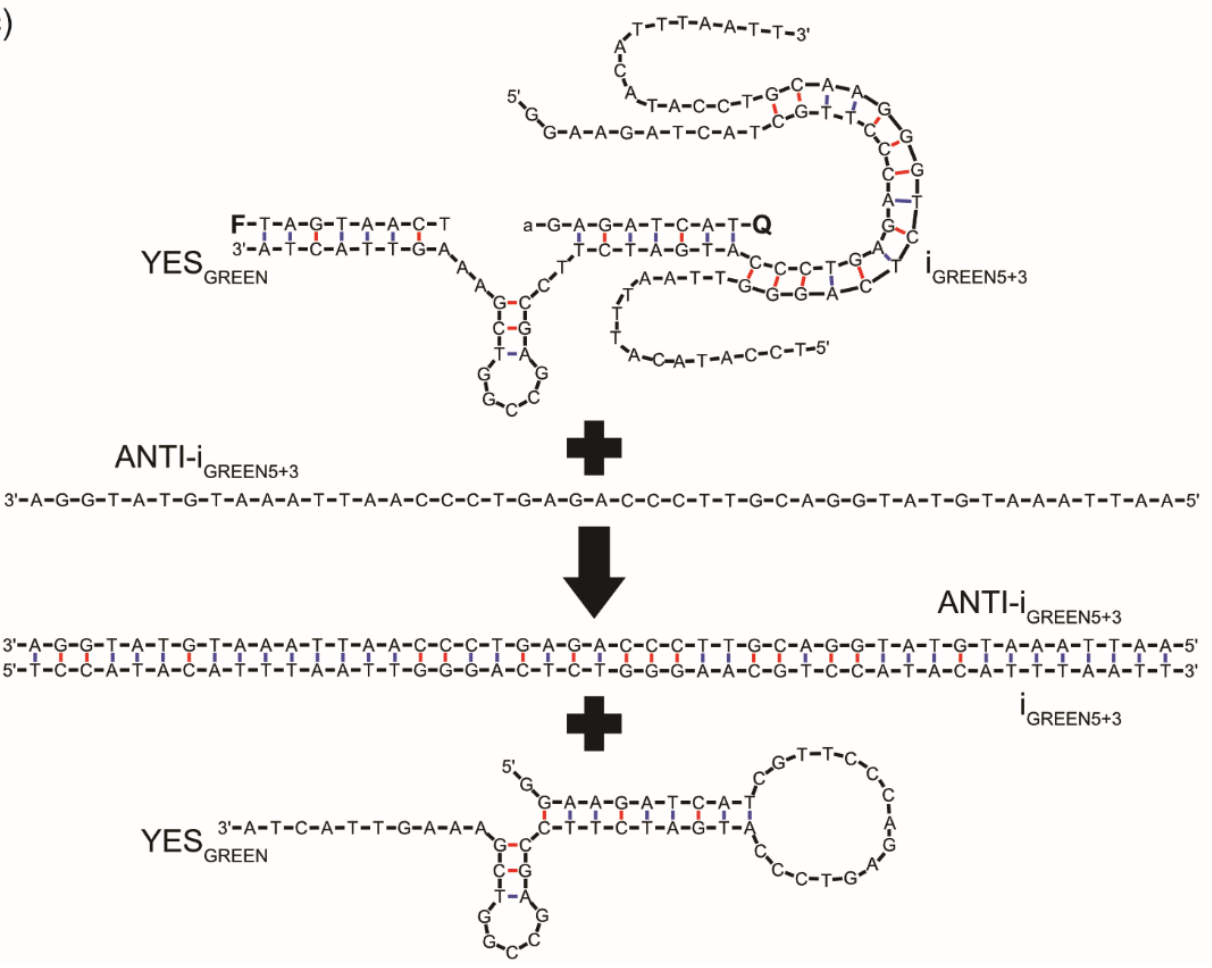

b)

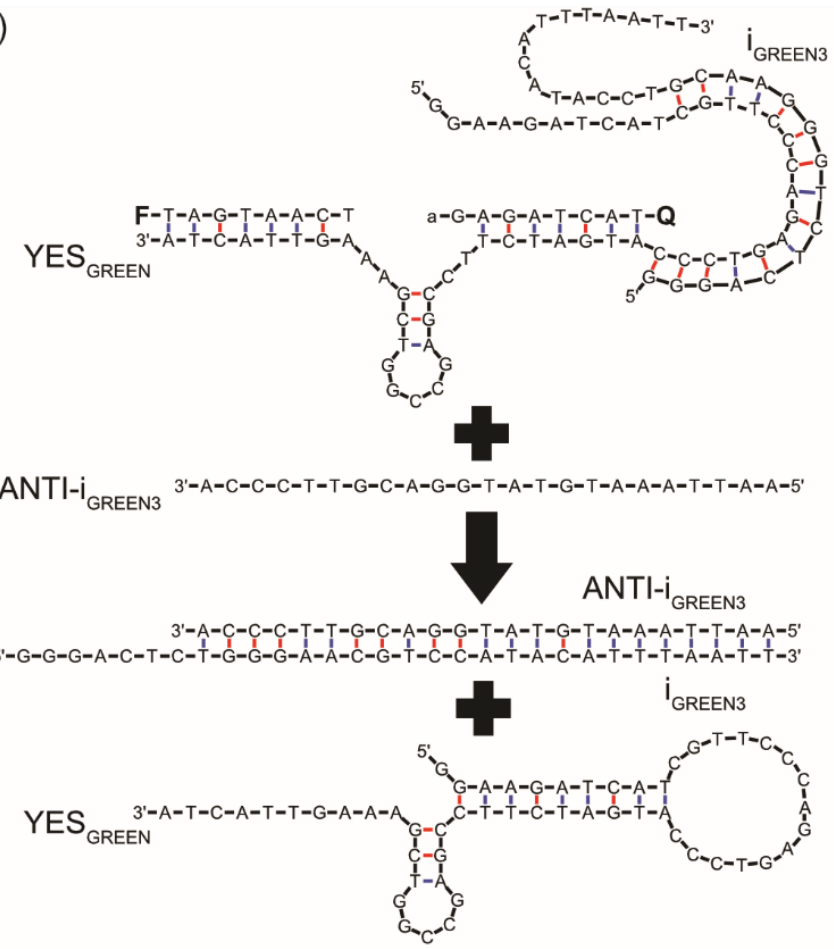

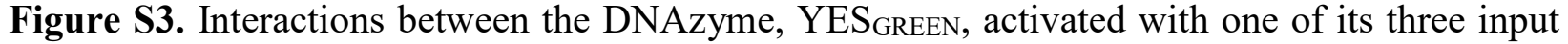
variants with an extended toehold region, and the inputs' respective ANTI-input, resulting in the formation of an input/ANTI-input complex and the deactivation of the DNAzyme. a) Interactions with 5' extended toehold region on input ssDNA (i $\mathrm{i}_{\text {GREEN5 }}$ and ANTI-i $\mathrm{i}_{\text {GREEN5); }}$ ); b) interactions with 3' extended toehold region on input ssDNA (i GREEN3 $_{3}$ and ANTI-i GREEN3 ); and, c) interactions with dual extended toehold regions on input ssDNA (i $\mathrm{i}_{\text {GREEN5+3 }}$ and ANTI-i GREEN5+3). $_{\text {. }}$. 
a)

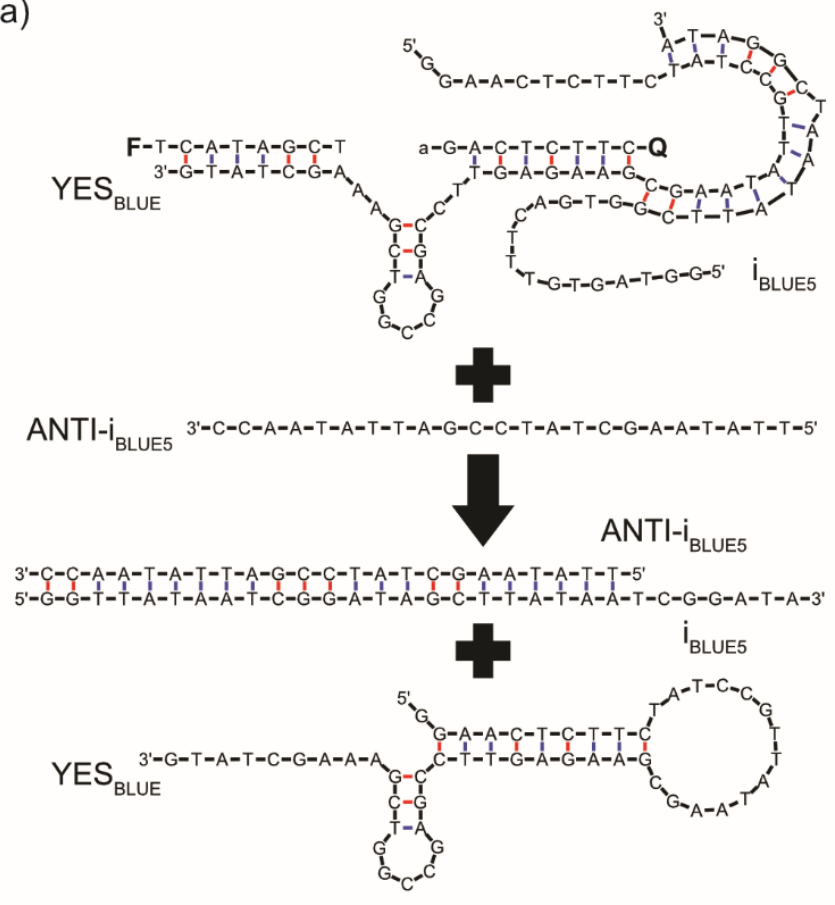

b)
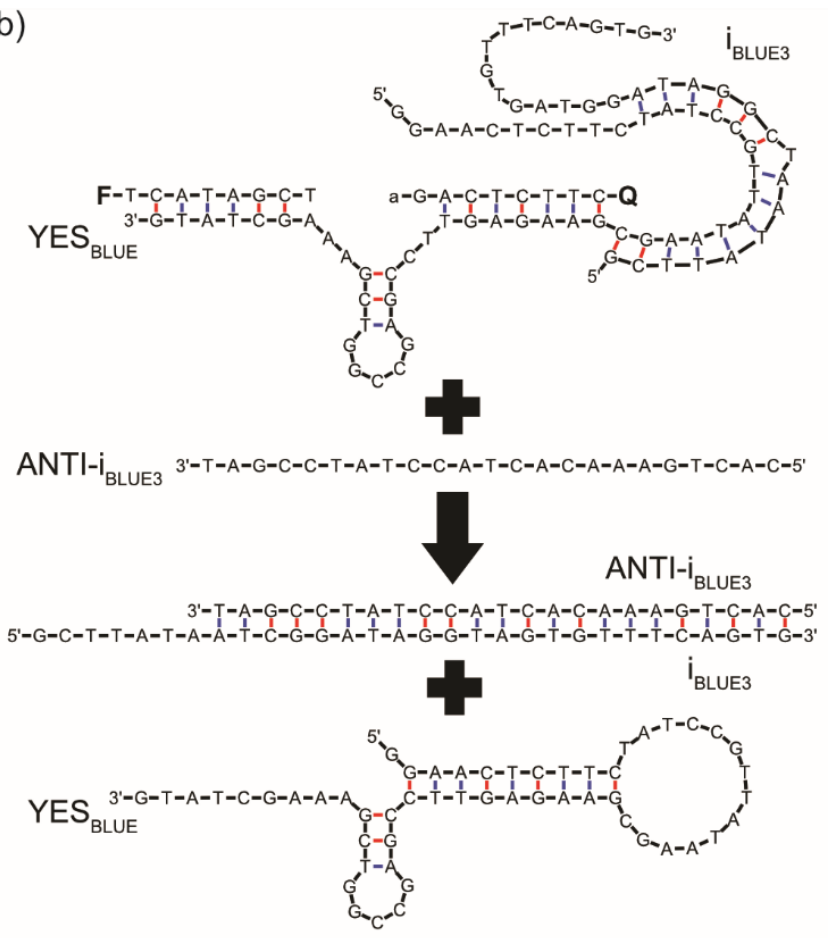

c)

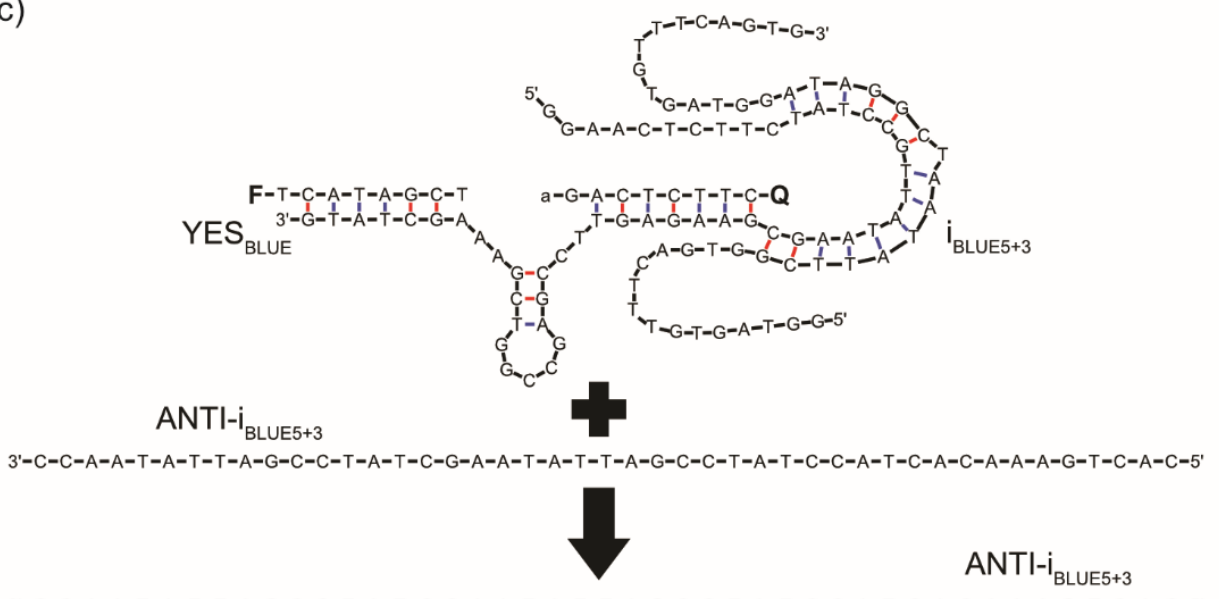

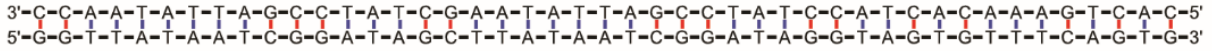

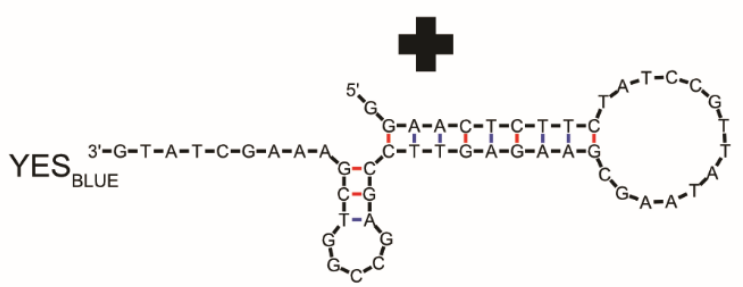

$\mathrm{i}_{\text {BLUE5 }+3}$

Figure S4. Interactions between the DNAzyme, YES variants with an extended toehold region, and the inputs' respective ANTI-input, resulting in the formation of an input/ANTI-input complex and the deactivation of the DNAzyme. a) Interactions with 5' extended toehold region on input ssDNA (i BLUE5 and ANTI-i BLUE5$_{\text {) }}$; b) interactions with 3' extended toehold region on input ssDNA (iBLUE3 and ANTI-i BLUE3); $_{\text {and, }}$ c) interactions with dual extended toehold regions on input ssDNA (iBLUE5+3 and ANTI-iBLUE5+3). 


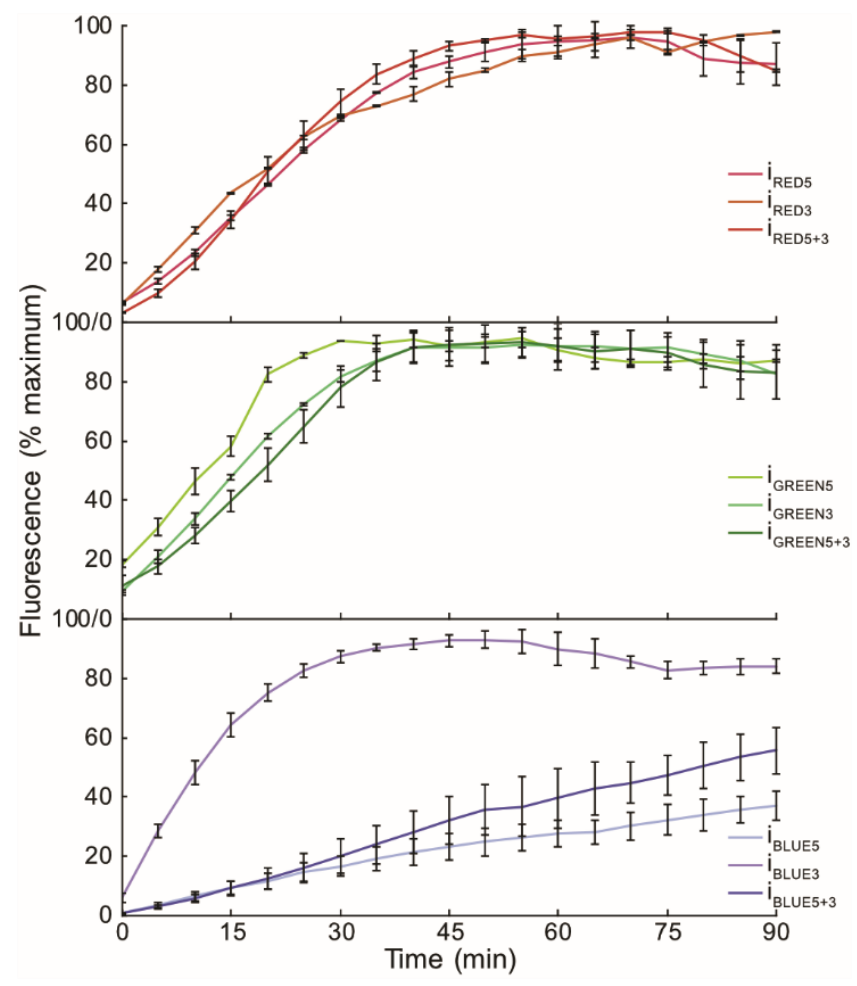

Figure S5. Fluorescence (mean \pm standard deviation) produced by the activity of the three

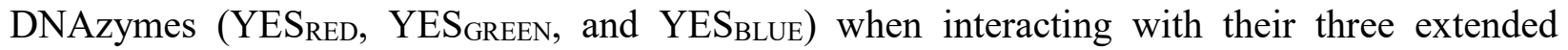
toehold input variants (5' extended toehold, 3' extended toehold, and dual extended toehold). Fluorescence shown is after the subtraction of the background DNAzyme activity in the absence of their inputs. 


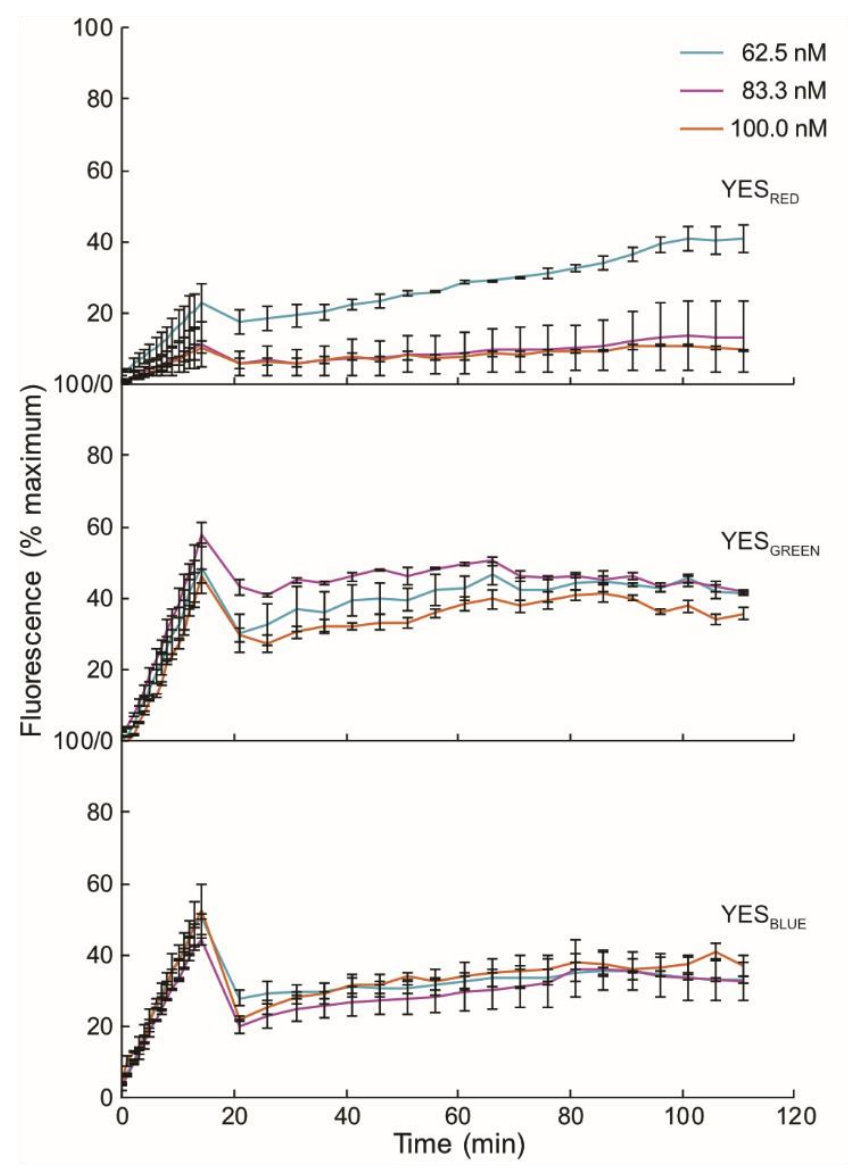

Figure S6. Elimination of fluorescence (mean \pm standard deviation) of a halted logic reaction via addition of ANTI-input and secondary quencher, where the concentration of added secondary quencher was calculated against expected fluorescence levels based on the amount of time elapsed after the reactions had been initiated. In this case, reactions were ceased at 15 minutes, resulting in a calculated amount of secondary quencher of $83.3 \mathrm{nM}$ in $50 \mu \mathrm{L}$ (purple line). NB: Elimination of fluorescence was considered unsuccessful due to inconsistencies and lack of fluorescence removed compared with expected amounts. 
Table S1. Oligonucleotide sequences for DNAzymes (YES gates), substrates (S; 'rA' denotes ribonucleotide adenosine), secondary quenchers (ANTI-S), inputs (i), extended toehold inputs $\left(i_{5}, i_{3}\right.$, and $\left.i_{5+3}\right)$, and input-complements (ANTI- $i_{5}$, ANTI-i $i_{3}$, and ANTI- $i_{5+3}$ ). All sequences are 5' to 3' (left to right), with colours matching in-text schematics.

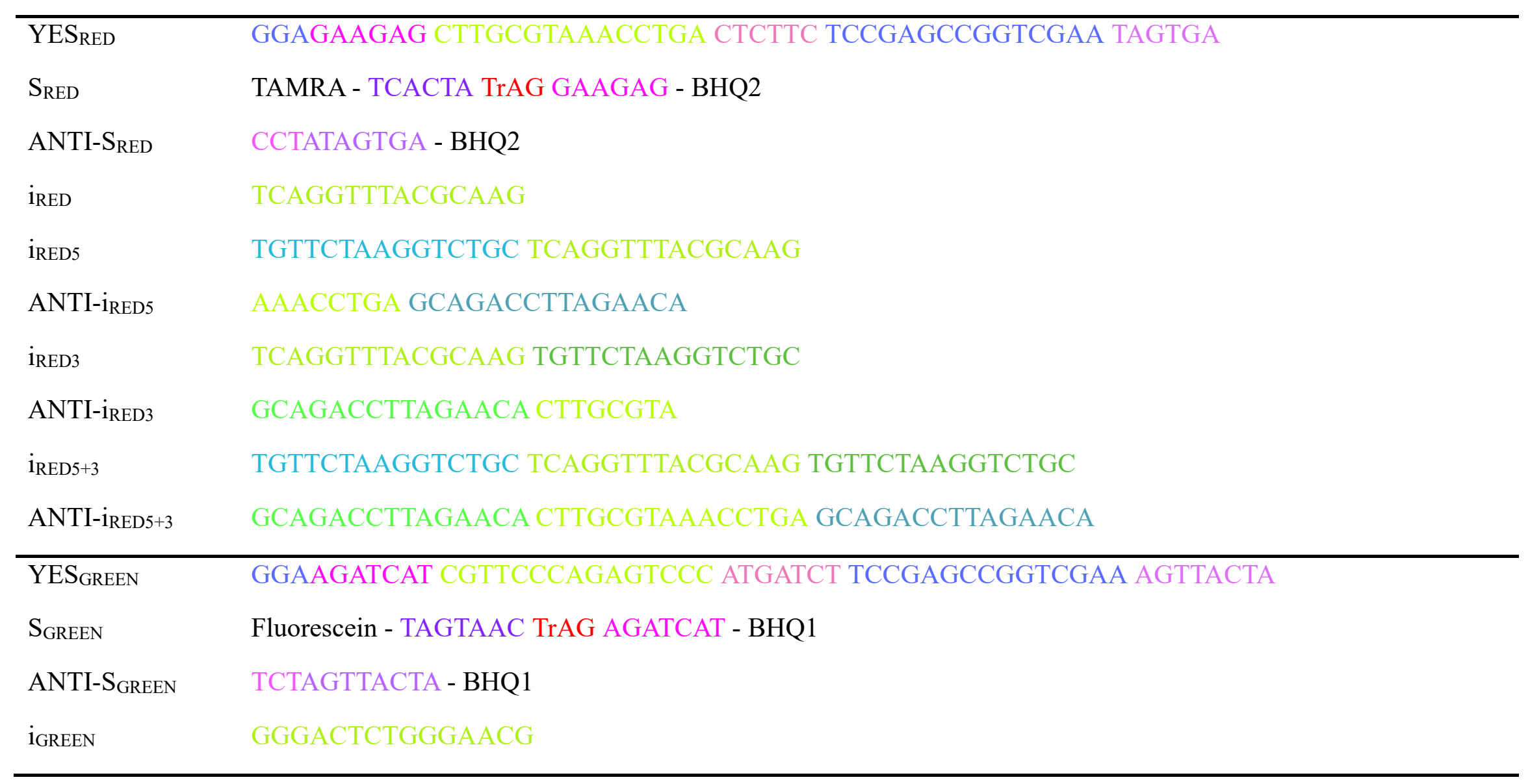


Table S1 cont'd.

\begin{tabular}{|c|c|}
\hline$\overline{i_{\text {GREEN5 }}}$ & $\begin{array}{l}\text { TCCATACATTTAATT GGGACTCTGGGAACG } \\
\end{array}$ \\
\hline $\mathrm{i}_{\text {GREEN3 }}$ & GGGACTCTGGGAACG TCCATACATTTAATT \\
\hline ANTI-i $i_{\text {GREEN3 }}$ & AATTAAATGTATGGA CGTTCCCA \\
\hline $\mathrm{i}_{\mathrm{GREEN} 5+3}$ & TCCATACATTTAATT GGGACTCTGGGAACG TCCATACATTTAATT \\
\hline $\mathrm{YES}_{\mathrm{BLUE}}$ & GGAACTCTTC TATCCGTTATAAGC GAAGAGT TCCGAGCCGGTCGAA AGCTATG \\
\hline S BLUE & Pacific blue - TCATAGC TrAG ACTCTTC - dabcyl \\
\hline ANTI-SBLUE & CTAGCTATGA - dabcyl \\
\hline iBLUE3 & GCTTATAATCGGATA GGTAGTGTTTCAGTG \\
\hline ANTI-iBLUE3 & CACTGAAACACTACC TATCCGAT \\
\hline $\mathrm{i}_{\text {BLUE5+3 }}$ & GGTAGTGTTTCAGTG GCTTATAATCGGATA GGTAGTGTTTCAGTG \\
\hline ANTI-iBLUE $5+3$ & CACTGAAACACTACC TATCCGATTATAAGC CACTGAAACACTACC \\
\hline
\end{tabular}


Table S2. In-well concentration of components in the logic reactions at time points of additions for cyclical activation/deactivation limitation test (Figure $3 \mathrm{~b}$ ). Additions of ON state are $10 \mu \mathrm{M}$ input ssDNA in $1 \mu \mathrm{L}$, and OFF state are $10 \mu \mathrm{M}$ ANTI-input in $1 \mu \mathrm{L}$. NB: Total volume of the reactions is increasing by $1 \mu \mathrm{L}$ per addition, resulting in the changing concentrations of tic-tac-toe buffer components, DNAzyme, and substrate.

\begin{tabular}{|c|c|c|c|c|c|c|c|c|c|}
\hline \multirow[b]{2}{*}{ time $(\min )$} & \multirow{2}{*}{$\begin{array}{c}\text { state } \\
(\mathrm{ON} / \mathrm{OFF})\end{array}$} & \multirow{2}{*}{$\begin{array}{c}\text { volume } \\
\text { (total } \mu \mathrm{L} \text { ) }\end{array}$} & \multicolumn{3}{|c|}{ tic-tac-toe buffer } & \multicolumn{4}{|c|}{ oligonucleotides } \\
\hline & & & $\begin{array}{c}\text { HEPES } \\
(\mathrm{mM})\end{array}$ & $\begin{array}{l}\mathrm{NaCl} \\
(\mathrm{mM})\end{array}$ & $\begin{array}{c}\mathrm{ZnCl}_{2} \\
(\mu \mathrm{M})\end{array}$ & $\begin{array}{c}\text { DNAzyme } \\
(\mathrm{nM})\end{array}$ & $\begin{array}{c}\text { substrate } \\
(\mathrm{nM})\end{array}$ & $\begin{array}{l}\text { input } \\
(\mathrm{nM})\end{array}$ & $\begin{array}{c}\text { ANTI- } \\
\text { input (nM) }\end{array}$ \\
\hline 0 & $\overline{\mathrm{ON}}$ & 50 & 40.0 & 800.0 & 800.0 & 50.0 & 250.0 & 100.0 & 0.0 \\
\hline 15 & OFF & 51 & 39.2 & 784.3 & 784.3 & 49.0 & 245.1 & 98.0 & 196.1 \\
\hline 30 & $\mathrm{ON}$ & 52 & 38.5 & 769.2 & 769.2 & 48.1 & 240.4 & 288.5 & 192.3 \\
\hline 45 & OFF & 53 & 37.7 & 754.7 & 754.7 & 47.2 & 235.8 & 283.0 & 377.4 \\
\hline 60 & $\mathrm{ON}$ & 54 & 37.0 & 740.7 & 740.7 & 46.3 & 231.5 & 463.0 & 370.4 \\
\hline 75 & OFF & 55 & 36.3 & 727.3 & 727.3 & 45.5 & 227.3 & 454.5 & 545.5 \\
\hline 90 & ON & 56 & 35.7 & 714.3 & 714.3 & 44.6 & 223.2 & 625.0 & 535.7 \\
\hline
\end{tabular}


Table S3. In-well concentrations of components in logic reactions at time points of additions for iteration of logical state cycling (Figure 5). Additions of ON state are $10 \mu \mathrm{M}$ input ssDNA and $12.5 \mu \mathrm{M}$ substrate in $1 \mu \mathrm{L}$, and OFF state are $10 \mu \mathrm{M}$ ANTI-input and $12.5 \mu \mathrm{M}$ secondary quencher in $1 \mu \mathrm{L}$. NB: Total volume of the reactions is increasing by $1 \mu \mathrm{L}$ per addition, resulting in the changing concentrations of tic-tac-toe buffer components and DNAzyme.

\begin{tabular}{|c|c|c|c|c|c|c|c|c|c|c|}
\hline \multirow[b]{2}{*}{$\begin{array}{l}\text { time } \\
(\mathrm{min})\end{array}$} & \multirow[b]{2}{*}{$\begin{array}{c}\text { state } \\
(\mathrm{ON} / \mathrm{OFF})\end{array}$} & \multirow[b]{2}{*}{$\begin{array}{l}\text { volume } \\
\text { (total } \mu \mathrm{L} \text { ) }\end{array}$} & \multicolumn{3}{|c|}{ tic-tac-toe buffer } & \multicolumn{5}{|c|}{ oligonucleotides } \\
\hline & & & $\begin{array}{c}\text { HEPES } \\
(\mathrm{mM})\end{array}$ & $\begin{array}{l}\mathrm{NaCl} \\
(\mathrm{mM})\end{array}$ & $\begin{array}{c}\mathrm{ZnCl}_{2} \\
(\mu \mathrm{M})\end{array}$ & $\begin{array}{l}\text { DNAzyme } \\
(\mathrm{nM})\end{array}$ & $\begin{array}{c}\text { substrate } \\
(\mathrm{nM})\end{array}$ & $\begin{array}{l}\text { secondary } \\
\text { quencher } \\
(\mathrm{nM})\end{array}$ & $\begin{array}{l}\text { input } \\
(\mathrm{nM})\end{array}$ & $\begin{array}{c}\text { ANTI- } \\
\text { input (nM) }\end{array}$ \\
\hline 0 & $\mathrm{ON}$ & 50 & 40.0 & 800.0 & 800.0 & 50.0 & 250.0 & 0.0 & 100.0 & 0.0 \\
\hline 19 & OFF & 51 & 39.2 & 784.3 & 784.3 & 49.0 & 245.1 & 245.1 & 98.0 & 196.1 \\
\hline 41 & ON & 52 & 38.5 & 769.2 & 769.2 & 48.1 & 480.7 & 240.4 & 288.5 & 192.3 \\
\hline 62 & OFF & 53 & 37.7 & 754.7 & 754.7 & 47.2 & 471.7 & 471.7 & 283.0 & 377.4 \\
\hline 83 & ON & 54 & 37.0 & 740.7 & 740.7 & 46.3 & 694.4 & 463.0 & 463.0 & 370.4 \\
\hline 104 & OFF & 55 & 36.3 & 727.3 & 727.3 & 45.5 & 681.8 & 681.8 & 454.5 & 545.5 \\
\hline 125 & ON & 56 & 35.7 & 714.3 & 714.3 & 44.6 & 892.9 & 669.6 & 625.0 & 535.7 \\
\hline
\end{tabular}

